\title{
Crushing Behavior and Crushing Strengths of Low-Density Foam Concrete
}

\author{
Yu Song ${ }^{1, *}$ and David A. Lange ${ }^{2}$ \\ ${ }^{1}$ Research Assistant, Department of Civil and Environmental Engineering, University of Illinois, IL \\ 61801-2352, US \\ ${ }^{2}$ Professor, Department of Civil and Environmental Engineering, University of Illinois, IL 61801- \\ 2352,US; dlange@illinois.edu
}

Correspondence: yusong3@illinois.edu

\begin{abstract}
Foam concrete is a highly cellularized cementitious material that undergoes extensive plastic deformation when loaded to failure. Under compression, the foam structure gets progressively crushed at a steady stress stage such that a substantial amount of energy is dissipated. Understanding foam concrete crushing behavior is of special importance for its engineering applications such as energy absorber, but the current studies are insufficient to define material properties for design of field applications. This study characterizes the crushing strength and foam modulus of samples with penetration test and resonant frequency test, respectively. A four-phase crushing behavior is observed. The yield strength and plateau strength are identified to characterize the foam crushing. Using the experimental inputs, the modulus-strength constitutive equations are then established. These findings are useful for expanding the knowledge of normal concrete to studies on foam concrete, as well as design of applications.
\end{abstract}

Keywords: cellular concrete, cellular material, foam concrete, foam material, crushable foam, crushing strength, mechanical property, foam modulus 


\section{INTRODUCTION}

Foam concrete is commonly used for landfilling in the construction industry, but it also shows a potential for impact absorption applications. This unique foam structure has a profound impact on its crushing behavior and mechanical property. In contrast to normal concrete which has a density around $2.3 \mathrm{~g} / \mathrm{cm}^{3}$ (144 pcf) and a compressive strength between 20 to $40 \mathrm{MPa}$ (2901 to $5802 \mathrm{psi}$ ), the foam concrete strength can be as low as $0.2 \mathrm{MPa}(29 \mathrm{psi}$ ) at its minimal density of $0.3 \mathrm{~g} / \mathrm{cm}^{3}$ (19 pcf). ${ }^{1-3}$ As a result, foam concrete is described as a low-density controlled low-strength material (LD-CLSM) in ACI specifications. ${ }^{4,5}$ With a density between 0.8 to $1.8 \mathrm{~g} / \mathrm{cm}^{3}$ (50 to $112 \mathrm{pcf}$ ), this material is mostly a closed cell foam that behaves closer to solid material. Lower than $0.4 \mathrm{~g} / \mathrm{cm}^{3}$ (25 pcf), the fresh mixture begins to lose its volume stability before hardening. ${ }^{6}$ Currently, foam concrete is mostly used functionally for flowable fill applications due to its lightweight nature and ease of excavation, and acoustic and thermal isolation due to its cellularized structure. ${ }^{1}$

Probing the structural potential of foam concrete has been a prevailing goal of the majority studies for decades. As reviewed by Ramamurthy et al., the compressive strength of foam concrete of 0.8 to $1.8 \mathrm{~g} / \mathrm{cm}^{3}$ (50 to $112 \mathrm{pcf}$ ) is the most frequently investigated structural property. ${ }^{7,8}$ It has been well established that the foam concrete strength decreases remarkably with the reduction in foam density, which plays a primary role in controlling the strength. ${ }^{9-11}$ Some strength related factors commonly considered on concrete are covered, including waterto-cementitious $(\mathrm{w} / \mathrm{cm})$ ratio, ${ }^{12-15}$ pozzolanic materials, ${ }^{14-18}$ and curing methods. ${ }^{13,14,19,20}$ The strength influence from fine aggregate inclusion on foamed mortar is often inspected more independently. ${ }^{4,21,22}$ Other structural properties studied by researchers include flexural and tensile strength..$^{7,9,16,23}$ To date, the structural potential of high-density foam concrete is still controversial, ${ }^{1,2}$ while the strength characterization for low-density foam concrete remains challenging. Meanwhile, interests have been growing in recent years of using this material in 
nature of a solid crushable foam for energy absorbing purposes, especially for low-density foam concrete. An example in this regard is engineered material arresting system (EMAS) for airport runway safety. ${ }^{24-27}$

For either the structural or energy absorbing applications, the studies to date are insufficient to render a clear understanding of how response of the foam concrete strength to its material property. Although a few investigations attempted to link the static Young's modulus to the compressive strength directly and by additionally considering the foam density, ${ }^{2,23,28}$ they are limited to provide a universal insight for foam concrete modulus-strength relationship. For instance, the foam density alone may not indicate the foam structure accurately, as the paste density also varies. Furthermore, more attention is anticipated for the low-density foam concrete less than $0.8 \mathrm{~g} / \mathrm{cm}^{3}(50 \mathrm{pcf})$.

This study proposes a new methodology for investigating the modulus-strength constitutive relationship of low-density foam concrete. This study only focuses on foamed cement paste so that fine aggregate inclusion is not considered. As a crushing represents a more general material failure scenario of foam materials, a penetration test is carried out to characterize the crushing behavior and crushing strength of foam concrete. In addition, a resonant frequency test is used to measure the dynamic Young's modulus of foam concrete, due to its nondestructive nature and good accuracy. ${ }^{29}$ The foam concrete samples are prepared with paste mixtures of different w/cm ratio and fly ash content, and foam densities ranging from 0.4 to $0.8 \mathrm{~g} / \mathrm{cm}^{3}$ (25 to $50 \mathrm{pcf}$ ) to cover the majority crushable foam concrete. Based on the testing results, the foam concrete crushing behavior is well defined as four phases, and two crushing strengths are identified for characterizing the crushing property. Furthermore, the experimental data are used for establishing the modulus-strength constitutive equations successfully, where strong correlations between the theoretical prediction and the measurement are achieved. 


\section{RESEARCH SIGNIFICANCE}

Foam concrete has a potential for value-added construction materials such as energy absorber, as well as accommodating high-volume recycled fines. However, the current studies are insufficient to characterize its material properties for design of field applications. This study studies the crushing strength and Young's modulus of a variety of foam concrete samples. After defining the key attributes to prescribe the foam crushing behavior, the modulus-strength constitutive equations are then established. Further analysis suggests that the foam crushing can be well predicted by knowing the paste modulus and relative density, which greatly facilitates design of foam concrete applications.

\section{BACKGROUND}

\section{Strengths of solid foam and normal concrete}

This study aims at investigating foam concrete crushing strength based on its relative density and the hardened paste property. The studies on cellular solid material reveal that the crushing strength of solid foam is governed by two aspects: the solid base material and the void system. ${ }^{30,31}$ The empirical equations proposed by Ashby to estimate the elastic yield strength and plastic yield strength of solid foams are given in Eq. 1 and 2, respectively: ${ }^{31}$

$$
\begin{aligned}
& \frac{\sigma_{e l}^{*}}{E_{s}}=c_{1}\left(\frac{\rho}{\rho_{s}}\right)^{2} \\
& \frac{\sigma_{p l}^{*}}{\sigma_{y}}=c_{2}\left(\frac{\rho}{\rho_{s}}\right)^{1.5}
\end{aligned}
$$

where $\sigma_{e l}^{*}$ and $\sigma_{p l}^{*}$ are the elastic and the plastic yield strength, $E_{s}$ and $\sigma_{y}$ are the elastic modulus and the yield strength of the solid base material, $c_{1}$ and $c_{2}$ are empirical constants obtained experimentally, and $\rho$ and $\rho_{s}$ are the densities of the foam and the solid. In these equations, the contribution from solid base material to foam strength is counted through $E_{S}$ and $\sigma_{y}$, and the influence from the void system is determined by the relative density, $\rho / \rho_{\mathrm{s} .} E_{s}$ is referred as solid modulus. 
Ashby also studied the crushing strength of brittle foams and developed the following relationship: ${ }^{31}$

$$
\frac{\sigma_{f}^{*}}{\sigma_{f}}=c_{3}\left(\frac{\rho}{\rho_{s}}\right)^{1.5}
$$

where $\sigma_{f}^{*}$ is the crushing strength of brittle foam, $\sigma_{f}$ is the flexural strength of base material, and $c_{3}$ is a constant. Although this equation showed a weaker correlation with the experimental data, the crushing strength of brittle foams is controlled by both the base material via $\sigma_{f}$ and the void system via $\rho / \rho_{\mathrm{s}}$. This equation uses the flexural strength of the base material to represent the solid property. However, the true value of flexural strength of hardened cement is not easy to obtain and a previous study showed poor correlation between this parameter and pore volume in cement paste. ${ }^{32}$ Furthermore, it is questionable whether this approach works for foam concrete, as concrete materials do not behave like pure brittle materials.

Since limited information on the flexural strength of the hardened cement paste is available, some insights are borrowed from studies on normal concrete. As recommended by ACI 318, the empirical relationships linking Young's modulus to the compressive yield strength and flexural strength of plain concrete are given in Eq. 5 and 6, respectively: ${ }^{33,34}$

$$
\begin{array}{ll}
E_{c}=4734\left(f_{c}^{\prime}\right)^{0.5} & \text { Eq. } 5 \\
f_{r}=0.62\left(f_{c}^{\prime}\right)^{0.5} & \text { Eq. } 6
\end{array}
$$

where $\mathrm{E}_{\mathrm{c}}$ is 28 -day static modulus of elasticity, $\mathrm{f}_{\mathrm{c}}{ }^{\prime}$ is 28 -day cylinder compressive strength, and $\mathrm{f}_{\mathrm{r}}$ is 28-day flexural strength, all with units in $\mathrm{N} / \mathrm{mm}^{2}$.

\section{Young's modulus of foam concrete}

In a recent study, it is proven that Young's modulus of foam concrete is predictable if the relative density and solid modulus are known: ${ }^{29}$

$$
\frac{E}{E_{s}}=\left(\frac{\rho}{\rho_{s}}\right)^{2}
$$


where E is Young's modulus of foam concrete, and $\mathrm{E}_{\mathrm{s}}$ is Young's modulus of the hardened paste. For conciseness, the $\mathrm{E}$ is referred as foam modulus in the rest of this paper. This equation provides an important function to bridge foam modulus to solid modulus of foam concrete.

\section{From Young's modulus to crushing strength of foam concrete}

In comparison to using flexural strength to indicate the hardened property, the solid or foam modulus of foam concrete has several outstanding advantages to serve the same function. First, the solid modulus is a fundamental property that governs a number of mechanical properties, including the flexural strength. ${ }^{33}$ Second, solid modulus has been proven feasible to predict foam strength in Eq.1. Third, both the foam and the solid moduli of foam concrete can be experimentally determined, and further interchangeable using Eq. 7.

Therefore, it is reasonable to hypothesize that the foam concrete crushing strength can be estimated using the solid or foam modulus. As foam modulus is directly measured from foam concrete, it should perform better than solid modulus. As such, an equation generalized in the form of Eq. 1-3 was proposed for predicting the crushing yield strength of foam concrete:

$$
\frac{\sigma_{f c}}{(E)^{a}}=k\left(\frac{\rho}{\rho_{s}}\right)^{b}
$$

where $\sigma_{\mathrm{fc}}$ is foam concrete yield strength under indentation, and $\mathrm{a}, \mathrm{b}$, and $\mathrm{k}$ are constants to be determined. Thus, characterizing the correlation between the crushing strength and the foam modulus, and essentially the solid modulus, is of special importance to this study.

\section{EXPERIMENTAL PROCEDURE}

\section{Mixture design}

Three groups of foam concrete mixtures with different paste mixtures were prepared in this study, where different w/cm ratio and fly ash replacement of cement were used. The mixing design is provided in Table 1. Design of the foam concrete mixtures followed the guideline specified in ASTM C796. ${ }^{35}$ For each group of paste mixtures, a pure paste sample and five 
foamed paste samples with density from 0.4 to $0.8 \mathrm{~g} / \mathrm{cm}^{3}$ ( 25 to $50 \mathrm{pcf}$ ) were prepared. Further reducing the density raised the foam instability issue significantly. As the control group, Group C (i.e., controlled) samples had a w/cm ratio of 0.42 and a $10 \%$ class $\mathrm{C}$ fly ash replacement. In comparison, a larger fly ash replacement of 30\% was used for Group HF (i.e., high-fly ash) samples, and a higher w/cm ratio of 0.47 was used for Group HW (i.e., high-water). As listed in Table 1, the sample name designation in this paper indicates the paste mixture type and the target density.

Table 1-Mixture design of the samples

\begin{tabular}{|c|c|c|c|c|c|}
\hline Mix \# & $\begin{array}{l}\text { Target } \\
\text { density } \\
{[\mathrm{g} / \mathrm{cm} 3]}\end{array}$ & $\begin{array}{c}\text { Fly ash } \\
\text { replacement } \\
{[\%]}\end{array}$ & $\mathrm{w} / \mathrm{c}$ & $\begin{array}{l}\text { Bulk density } \\
{[\mathrm{g} / \mathrm{cm} 3]}\end{array}$ & $\begin{array}{l}\text { Relative } \\
\text { density }\end{array}$ \\
\hline C_0.4 & 0.4 & \multirow{6}{*}{10} & \multirow{6}{*}{0.42} & 0.391 & 0.198 \\
\hline C_ 0.5 & 0.5 & & & 0.495 & 0.250 \\
\hline C_ 0.6 & 0.6 & & & 0.587 & 0.297 \\
\hline C_ 0.7 & 0.7 & & & 0.712 & 0.359 \\
\hline C_ 0.8 & 0.8 & & & 0.825 & 0.417 \\
\hline C_solid & 1.91 & & & 1.977 & 1 \\
\hline HF_0.4 & 0.4 & \multirow{6}{*}{30} & \multirow{6}{*}{0.42} & 0.400 & 0.210 \\
\hline HF_0.5 & 0.5 & & & 0.529 & 0.278 \\
\hline HF_0.6 & 0.6 & & & 0.609 & 0.319 \\
\hline HF_0.7 & 0.7 & & & 0.748 & 0.393 \\
\hline HF_0.8 & 0.8 & & & 0.837 & 0.439 \\
\hline HF_solid & 1.88 & & & 1.907 & 1 \\
\hline HW_0.4 & 0.4 & \multirow{6}{*}{10} & \multirow{6}{*}{0.47} & 0.414 & 0.216 \\
\hline HW_0.5 & 0.5 & & & 0.503 & 0.262 \\
\hline HW_0.6 & 0.6 & & & 0.576 & 0.300 \\
\hline HW_0.7 & 0.7 & & & 0.664 & 0.346 \\
\hline HW_0.8 & 0.8 & & & 0.755 & 0.393 \\
\hline HW_solid & 1.85 & & & 1.923 & 1 \\
\hline
\end{tabular}

(For unit conversion: $1 \mathrm{~g} / \mathrm{cm}^{3}=62.428 \mathrm{pcf}$ )

\section{Sample preparation}

The mixing procedures of the foam concrete samples were divided into three steps: paste mixing, aqueous foam preparation, and final blending. The paste mixing followed the 
procedures specified in ASTM C305. ${ }^{36}$ Portland cement (Type I), fly ash (class C), hardening accelerator $\left(32 \% \mathrm{CaCl}_{2}\right)$, superplasticizer (Sika ViscoCrete 2100), and water were used for paste mixing. The hardening accelerator was dosed at $8 \%$ by weight of cement powder. Depending on the actual mixing proportions, the superplasticizer was dosed individually to maintain the same high flowability for all paste mixtures.

For the aqueous foam preparation, the ratio between the foaming agent (BASF MasterCell 30) and tap water was 1:15. The solution was then foamed by a portable pail mixer to its maximum volume. All the liquid inputs including the chemical admixtures used for preparing the paste and the foam were considered to calculate the $\mathrm{w} / \mathrm{cm}$ ratio.

During the final blending, the foam was introduced into the fresh paste progressively with the pail mixer continuously stirring the mixture. The addition was stopped when the entire mixture reached to the designed volume, at which both target density and w/cm ratio were met. The mixture was further blended for another 30 s to ensure good homogeneity of void distribution.

After mixing, the fresh foam concrete was gently poured into $101.6 \times 203.2 \mathrm{~mm}(2 \times 4$ ") standard concrete cylinder and $50.8 \times 50.8 \times 203.2 \mathrm{~mm}(2 \times 2 \times 8$ ”) prism molds. For each sample, nine cylinders for penetration test and two prism specimens for resonant frequency test were cast. Then, the molds were sealed to allow mixture hardening for three days, after which the specimens were further cured in a $100 \% \mathrm{RH}$ environmental chamber at $21^{\circ} \mathrm{C}$. The bulk density of each sample was measured right after demolding, and additional measurements at later ages confirmed little change in the bulk density. During the sample preparation, any sample found its density off the target by more than $0.05 \mathrm{~g} / \mathrm{cm}^{3}$ (3 pcf)was recast. The density information of the final mixtures is provided in Table 1, along with the relative density.

\section{Characterization of the crushing behavior}


The crushing behavior and mechanical property of a solid foam are commonly characterized by analyzing its load-displacement curve from indentation. ${ }^{37-40}$ This test simulates a basic crushing scenario that is representative of a wide range of crushing, impacting, and indentation events. In this study, the test was carried out for the cylinder specimens at 7, 14, and 21 days after casting, as previous experiments suggested an imperceptible strength buildup after this period. ${ }^{29}$ At each testing date, three cylinders were tested for each foam concrete sample.

The penetration test was done with an Instron 4502 testing frame, as shown in Fig. 1. During the experiment, a steel rod of a $19.05 \mathrm{~mm}\left(0.75^{\prime \prime}\right)$ diameter was indented into the foam concrete cylinder vertically from the top center. The loading capacity of the Instron frame was $10 \mathrm{kN}$, which yielded a maximum indentation stress of $35 \mathrm{MPa}$ (5076 psi). The foam concrete cylinder was tested without demolding, and the loading was displacement controlled at a 75 $\mathrm{mm} / \mathrm{min}(2.95 \mathrm{inch} / \mathrm{min})$ rate, according to a previous study on glass foam. ${ }^{41}$ Previous lab tests suggested that the obtained load-displacement curve was not evidently affected by varying the loading rate from 10 to $500 \mathrm{~mm} / \mathrm{min}$ ( 0.39 to $19.7 \mathrm{inch} / \mathrm{min})$ and the plastic cylinder mold did not impose a difference on the test results.

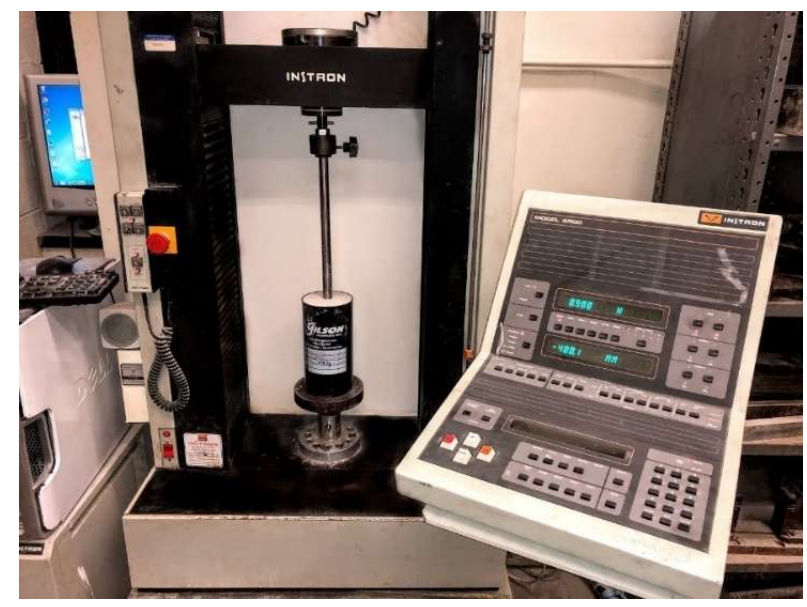

Fig. 1-Testing setup for the penetration test. The Instron 4052 loading frame is coupled with a $10 \mathrm{kN}$ load cell.

\section{Characterization of foam concrete Young's modulus}


Young's modulus of foam concrete was characterized to seek the protentional correlation to the crushing property. According to ASTM C215, ${ }^{42}$ Young's modulus of the two prism specimens of each sample was monitored by measuring the resonant frequency. The measurement was conducted at 7, 14, and 21 days after casting, in correspondence to the penetration test. The essential testing apparatus included an accelerometer (PCB, model 352C03) for measuring the resonance, a signal conditioner (PCB, model 482) for signal processing, and a DAQ (National Instruments, model 9171) for data acquisition. The sampling frequency was $200 \mathrm{kHz}$, giving a 4-Hz resolution in the frequency domain.

Due to better signal quality and higher accuracy in the modulus measurement of foam concrete, ${ }^{29}$ the transverse fundamental vibration mode of the prism specimens was excited in the test. After converting the measured time-domain vibration signals to frequency-domain signals through fast Fourier transform (FFT), the transverse vibration frequency was determined as the location of the strongest peak in the frequency-domain spectrum. ${ }^{42,43}$ For each specimen, three individual measurements were conducted at each time, and the foam modulus was calculated based on their average.

\section{RESULTS AND DISCUSSION}

\section{Foam concrete load-displacement response}

Analyzing the load-displacement behavior under indentation provides important insights for studying mechanical properties of cellular solids. Three load-displacement results representing the general crushing behavior of the foam concrete samples are given in Fig. 2. These curves compare the 7-day load-displacement behavior of three Group C specimens at $0.4,0.6$, and 0.8 $\mathrm{g} / \mathrm{cm}^{3}(25,38$, and $50 \mathrm{pcf})$. The ordinate value of indentation stress is obtained by dividing the load force over the nominal contact area of the indenter. The indentation was stopped at around $180 \mathrm{~mm}$ (7.09”), at which clear sign of final densification was seen. 


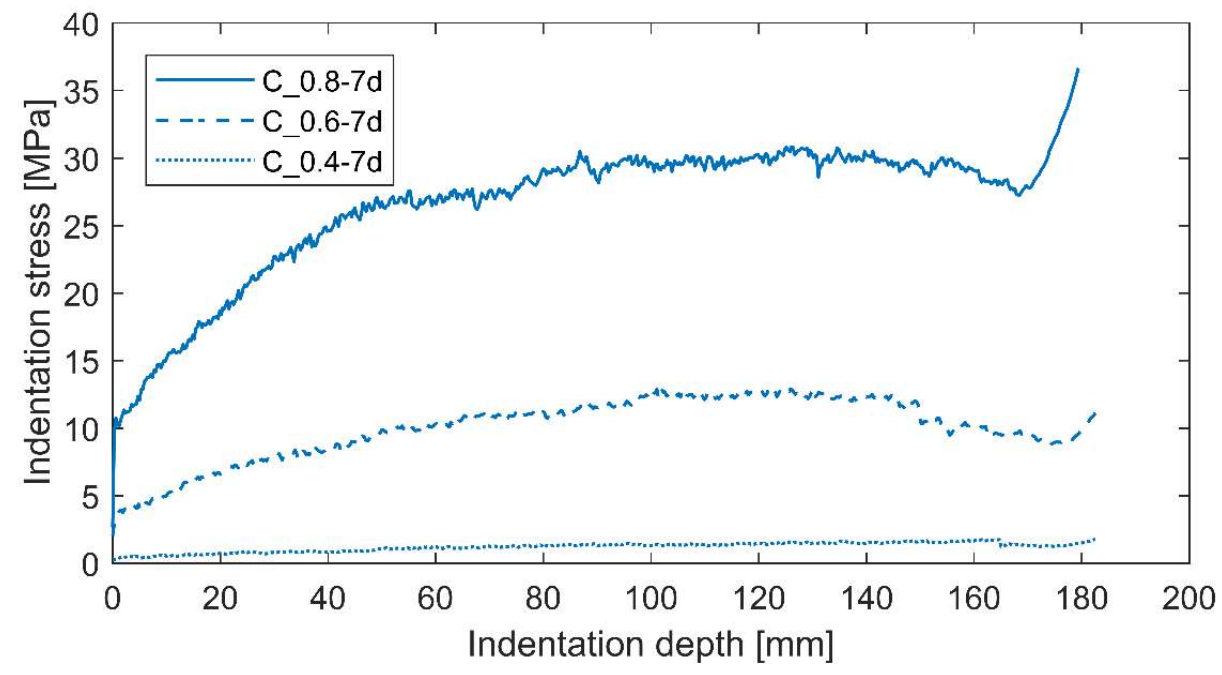

Fig. 2-A comparison of the load-displacement curves of three Group C specimens at 0.4, 0.6, and $0.8 \mathrm{~g} / \mathrm{cm}^{3}$. All the specimens are tested at 7 days after casting. (Note: $1 \mathrm{~g} / \mathrm{cm}^{3}=62.428 \mathrm{pcf}$, $1 \mathrm{MPa}=145.038 \mathrm{psi}$ )

A total of four crushing phases were identified for foam concrete. For a cellular material, it typically has three crushing phases, which are linear elastic, crushing plateau, and final densification. ${ }^{31}$ In addition to these phases, a transitional phase that bridges the elastic and the plateau phases is observed distinctively here. During this phase, the stress is built up to the plateau level at a relatively constant rate. This transitional phase has not been previously reported. Taking the C_0.8-7d as an example, the linear elastic phase corresponds to the instantaneous rise at the very beginning of the indentation, which ends at the yield strength of $10 \mathrm{MPa}(1450 \mathrm{psi})$. In the transitional phase, the stress further raises to $27 \mathrm{MPa}$ (3916 psi) at the penetration depth of $50 \mathrm{~mm}(1.97$ ") at a relatively constant rate, followed by a smooth transition to the plateau phase. The plateau phase that gives a consistent plateau strength of 30 $\mathrm{MPa}$ (4351 psi) is found from 80 to $160 \mathrm{~mm}$ (3.15 to 6.3”). Lastly, the final densification occurs when the indenter reaches the bottom of the sample, where the foam cannot be further compressed. The four crushing phases are also recognizable in C-0.6-7d and C-0.4-7d.

For all the curves shown in Fig. 2, two crushing strengths, a yield strength and a plateau 
strength, can be identified at the beginning of the transitional phase and the crushing plateau. The crushing strengths become progressively lower by the descent on foam density. In comparison to $\mathrm{C}-0.8-7 \mathrm{~d}$, it is clear for $\mathrm{C}-0.6-7 \mathrm{~d}$ that the ending point of the transitional phase is postponed to $100 \mathrm{~mm}$ (3.94"); for C-0.8-7d, this point is further delayed to $140 \mathrm{~mm}$ (5.51"). For all the tested specimens, it is observed that the transitional phase becomes increasingly longer when foam density goes down. At a low foam density such as $0.4 \mathrm{~g} / \mathrm{cm}^{3}$ ( $25 \mathrm{pcf}$ ), the slope of the transitional phase is infinitesimal so that it seems the plateau phase is obtained right after the elastic phase. Therefore, observation of the transitional phase should be attributed to foam density. As the density gets larger, the indentation stress builds up at a much higher rate, making the transitional phase more distinguishable.

\section{Local accumulation of the crushed foam under indenter at the four phases}

The four crushing phases relate to the local accumulation of the densified material underneath the indenter. To illustrate this phenomenon, the cross section of a 21-day C_0.6 specimen at the four phases is demonstrated in Fig. 3. In a close agreement to observations commonly seen in other cellular materials studies, the crushed material formed a cone-shaped region under the indenter, where this cone-shaped local densification is often referred to dead zone ${ }^{44,45}$ or passive cone. ${ }^{46}$

During the entire indentation process, the foam concrete only experienced internal volume collapse under the indenter. The top surface of a 21-day C_0.6 cylinder specimen is shown in Fig. 4. The crushed region of the cross section at the transitional phase shown in Fig. 3 is magnified for a demonstration in Fig. 5. After removing the indenter, a clean interface was observed, and the crushed foam exhibited minimal lateral expansion. Both observations suggested that the foam was crushed downward without cracking issue. This behavior was caused by the extremely low Poisson's ratio of low-density cellular solids. ${ }^{31,38,41,47}$ 

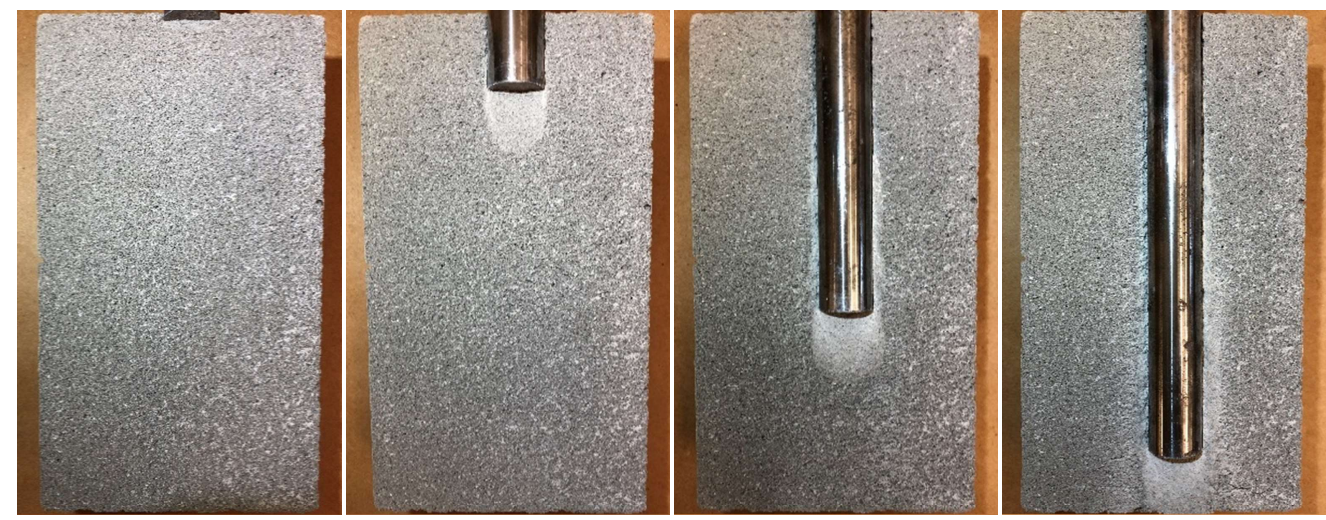

Fig. 3-Development of the local densification on the same cross section of a C_0.6 cylinder specimen. The crushing depths were 1,30,120, and $180 \mathrm{~mm}$, corresponding to the elastic, transitional, plateau phase, and densification crushing phases, respectively. The densified region is distinctive from the uncrushed foam.

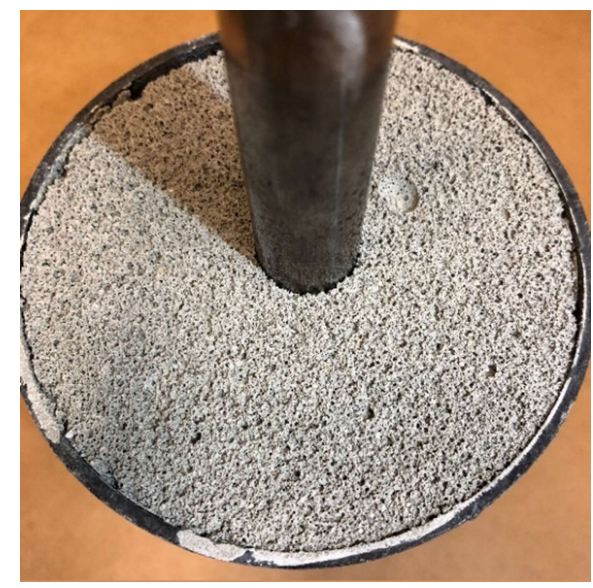

Fig. 4-Top surface of a C_0.6 cylinder specimen after the indentation test, in which no crack was seen.
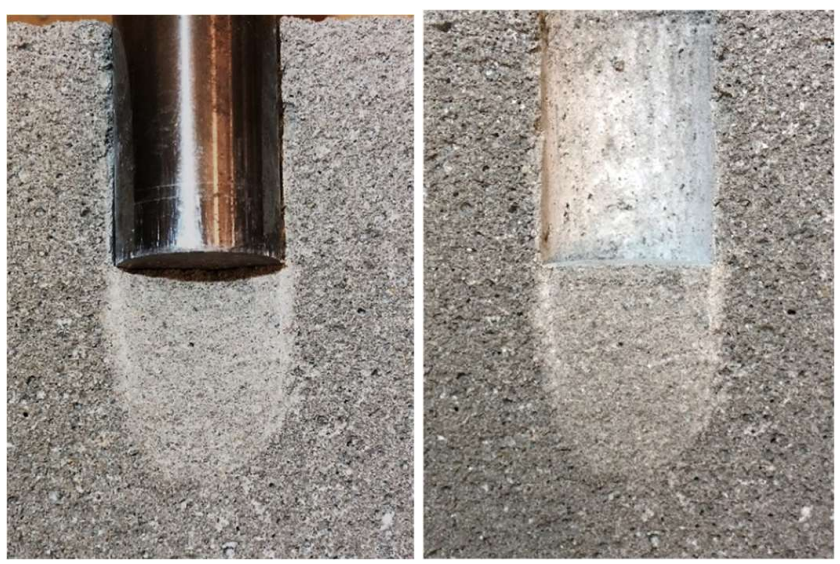

Fig. 5-Magnified view of the local densification of the C_0.6 specimen cross section, before and after removing the indenter. 
Further inspection on Fig $\mathbf{3}$ and $\mathbf{5}$ reveals that the transitional phase correlates strongly to the build-up of the densification cone during indentation, which also explains the different length of the transitional phase for different samples. As only the solid material contributes to the densification cone, this phase completes within a shorter indentation depth for the higher density foams. For a further understanding of the development energy dissipation during foam concrete crushing, this phenomenon is worth giving special attention, but this topic runs out of the interests of this paper.

\section{Characterization of yield strength and plateau strength of the samples}

As the yield strength and plateau strength are of special importance to characterize foam concrete crushing behavior, these parameters were measured from the load-displacement curve of each cylinder specimen. The yield strength was determined as the starting point of the transitional phase. The plateau strength was averaged from the plateau section of the loaddisplacement curve. The result of the strength measurement is summarized in Table 2, along with the density information of all samples. The yield strength and plateau strength values are shown with 4 and 3 significant digits, respectively. In this table, the data of each sample were averaged from the measurements on the three cylinder specimens, where the individual measurements were found to be highly identical. Note that the plateau strength of sample HF_0.8 at 14 and 21 days was not obtained, as the stress level run beyond the loading capacity of the testing frame.

In Table 2, there was a steep rise in both yield strength and plateau strength for all the foam samples when the density went up from 0.4 to $0.8 \mathrm{~g} / \mathrm{cm}^{3}$ (25 to $50 \mathrm{pcf}$ ). Continuous growth of the crushing strengths was observed over time. Due to the lower w/cm ratio and fly ash content, the paste mixture for Group C samples gained the highest strength among all, which resulted in higher crushing strengths seen in Group C samples. When foam density is the same, the 
paste strength plays a determinative role to foam concrete strength. This finding also corroborates the conclusion drawn in the many other studies on solid foam. . $^{7,10}$

Table 2-Testing results of yield strength and plateau strength of the samples

\begin{tabular}{|c|c|c|c|c|c|c|}
\hline \multirow{2}{*}{ Mix \# } & \multicolumn{2}{|c|}{ Yield strength $\sigma_{\mathrm{y}}[\mathrm{MPa}]$} & \multicolumn{3}{c|}{ Plateau stress $\sigma_{\mathrm{pl}}[\mathrm{MPa}]$} \\
\cline { 2 - 7 } & $7 \mathrm{~d}$ & $14 \mathrm{~d}$ & $21 \mathrm{~d}$ & $7 \mathrm{~d}$ & $14 \mathrm{~d}$ & $21 \mathrm{~d}$ \\
\hline C_0.4 & 0.2953 & 0.3533 & 0.4098 & 1.70 & 1.95 & 2.14 \\
\hline C_0.5 & 1.697 & 1.879 & 2.188 & 6.33 & 7.16 & 8.64 \\
\hline C_0.6 & 3.741 & 4.532 & 4.964 & 12.6 & 14.1 & 15.3 \\
\hline C_0.7 & 7.216 & 7.729 & 8.023 & 20.5 & 22.2 & 25.2 \\
\hline C_0.8 & 10.35 & 11.32 & 12.29 & 29.7 & 32.1 & 35.0 \\
\hline C_solid & - & - & - & - & - & - \\
\hline HF_0.4 & 0.2621 & 0.2678 & 0.2742 & 1.17 & 1.24 & 1.41 \\
\hline HF_0.5 & 0.8469 & 1.014 & 1.128 & 2.47 & 3.02 & 3.29 \\
\hline HF_0.6 & 2.319 & 2.623 & 2.822 & 6.58 & 7.40 & 8.46 \\
\hline HF_0.7 & 6.561 & 7.659 & 8.571 & 19.8 & 22.6 & 25.4 \\
\hline HF_0.8 & 11.64 & 14.15 & 15.09 & 32.8 & N/A & N/A \\
\hline HF_solid & - & - & - & - & - & - \\
\hline HW_0.4 & 0.3226 & 0.3365 & 0.3747 & 1.38 & 1.63 & 1.71 \\
\hline HW_0.5 & 1.589 & 2.016 & 2.306 & 7.09 & 8.42 & 9.51 \\
\hline HW_0.6 & 2.463 & 2.505 & 2.761 & 8.85 & 9.49 & 10.0 \\
\hline HW_0.7 & 3.628 & 3.761 & 3.8558 & 12.9 & 14.4 & 15.6 \\
\hline HW_0.8 & 6.571 & 8.588 & 9.062 & 24.9 & 30.9 & 34.5 \\
\hline HW_solid & - & - & - & - & - & - \\
\hline
\end{tabular}

(For unit conversion: $1 \mathrm{MPa}=145.038 \mathrm{psi}$ )

\section{Characterization of the foam and solid modulus}

As a fundamental material parameter, Young's modulus is critical for studying foam concrete. In the experimental work, the dynamic Young's modulus of the samples was interpreted based on the fundamental transverse frequency using resonant frequency test as specified by ASTM C215. For each foamed sample, the transverse frequency and Young's modulus results averaged from the two prism specimens are given in Table 3. Young's modulus of the samples was then calculated using Eq. 9 from ASTM C215: ${ }^{42}$

$$
E=C M n^{2}
$$


where $\mathrm{E}$ is dynamic Young's modulus; $\mathrm{C}$ is a geometry parameter; $\mathrm{M}$ is specimen mass; and $\mathrm{n}$ is transverse fundamental frequency.

Table 3-Testing results of fundamental transverse frequency and dynamic Young's modulus of the samples.

\begin{tabular}{|c|c|c|c|c|c|c|}
\hline \multirow{2}{*}{ Mix \# } & \multicolumn{3}{|c|}{ Transverse fundamental frequency [Hz] } & \multicolumn{3}{|c|}{ Dynamic young's modulus E [MPa] } \\
\cline { 2 - 7 } & $7 \mathrm{~d}$ & $14 \mathrm{~d}$ & $21 \mathrm{~d}$ & $7 \mathrm{~d}$ & $14 \mathrm{~d}$ & $21 \mathrm{~d}$ \\
\hline C_0.4 & 1235 & 1268 & 1316 & 463 & 488 & 526 \\
\hline C_0.5 & 1720 & 1828 & 1836 & 1138 & 1285 & 1297 \\
\hline C_0.6 & 1884 & 1956 & 2024 & 1619 & 1745 & 1868 \\
\hline C_0.7 & 2091 & 2116 & 2140 & 2415 & 2473 & 2530 \\
\hline C_0.8 & 2200 & 2256 & 2265 & 3104 & 3283 & 3290 \\
\hline C_solid & 3448 & 3512 & 3539 & 18255 & 18943 & 19236 \\
\hline HF_0.4 & 1084 & 1116 & 1144 & 365 & 387 & 407 \\
\hline HF_0.5 & 1200 & 1296 & 1751 & 591 & 690 & 744 \\
\hline HF_0.6 & 1591 & 1672 & 1696 & 1200 & 1325 & 1364 \\
\hline HF_0.7 & 1999 & 2076 & 2057 & 2333 & 2517 & 2660 \\
\hline HF_0.8 & 2208 & 2284 & 2340 & 3169 & 3391 & 3559 \\
\hline HF_solid & 3264 & 3383 & 3471 & 15783 & 16955 & 17853 \\
\hline HW_0.4 & 1152 & 1216 & 1264 & 427 & 476 & 514 \\
\hline HW_0.5 & 1700 & 1760 & 1804 & 1129 & 1210 & 1286 \\
\hline HW_0.6 & 1644 & 1728 & 1663 & 1212 & 1339 & 1457 \\
\hline HW_0.7 & 1872 & 1904 & 1896 & 1817 & 1880 & 1935 \\
\hline HW_0.8 & 2040 & 2120 & 2191 & 2450 & 2646 & 2826 \\
\hline HW_solid & 3192 & 3305 & 3400 & 15227 & 16322 & 17276 \\
\hline
\end{tabular}

(For unit conversion: $1 \mathrm{MPa}=145.038 \mathrm{psi}$ )

Similar to the observations on the crushing strengths in Table 2, the foam modulus results were found to positively correlate with foam density, age, and the property of the hardened paste. For the same group of samples, a higher foam modulus always corresponded to larger crushing strengths for each sample. By influencing both foam modulus (see Eq. 7) and hardened paste strength, the solid modulus is a major factor governing the foam concrete crushing behavior. 


\section{Yield strength and plateau strength}

The plateau strength seems to be correlated with the yield strength, based on the data given in

Table 2. The yield strength and plateau strength results for each sample group are compared individually in Fig. 6. The dashed line in these plots is the linear curve fitting, along with the fitting equation and the coefficient of determination, $\mathrm{R}^{2}$, to indicate the fitting quality. The results of $\mathrm{R}^{2}$ in the three plots of Fig. 6 are all close to 1, suggesting a remarkable correlation between these two parameters. For Group $\mathrm{C}$ samples in Fig. 6 (a), the curve fitting finds a plateau-to-yield strength ratio of 2.93. Regardless of the foam density, the plateau strength is about three times of the yield strength in this case. In comparison, a slightly smaller ratio of 2.91 is found for Group HF samples in Fig. 6 (b); however, the ratio becomes 3.76 for Group HW samples in Fig. 6 (c). These results suggest that the plateau-to-yield strength is only relevant to the hardened paste property, meaning that the plateau strength can be potentially predicted from the yield strength that is easier to measure. This finding gives a useful insight for simplifying the relationship of foam concrete crushing strengths.

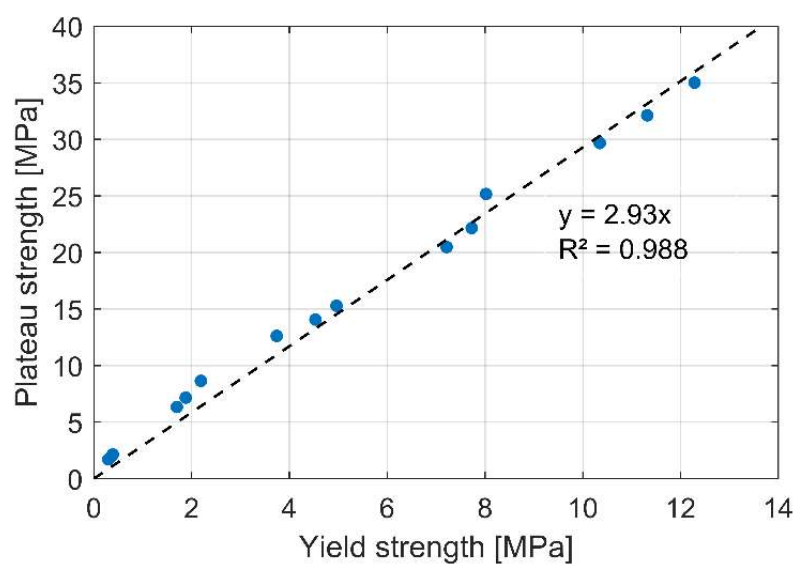

(a) 


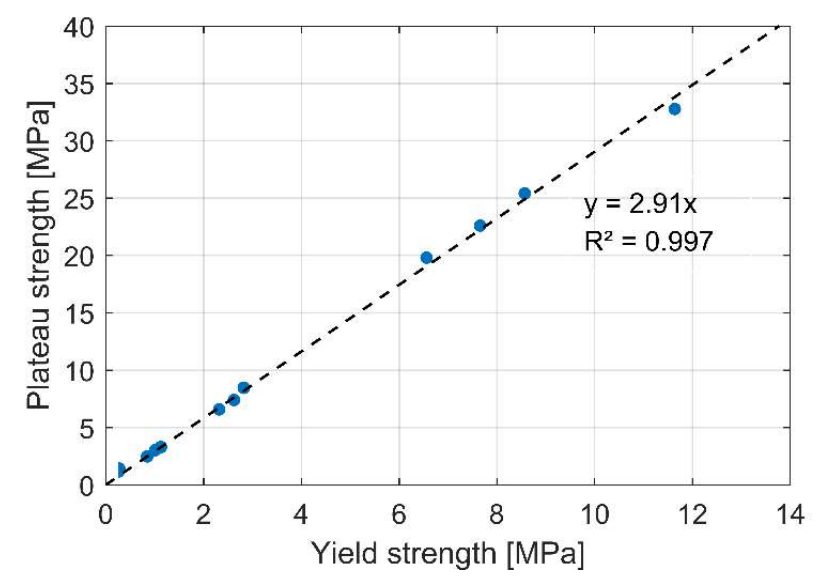

(b)

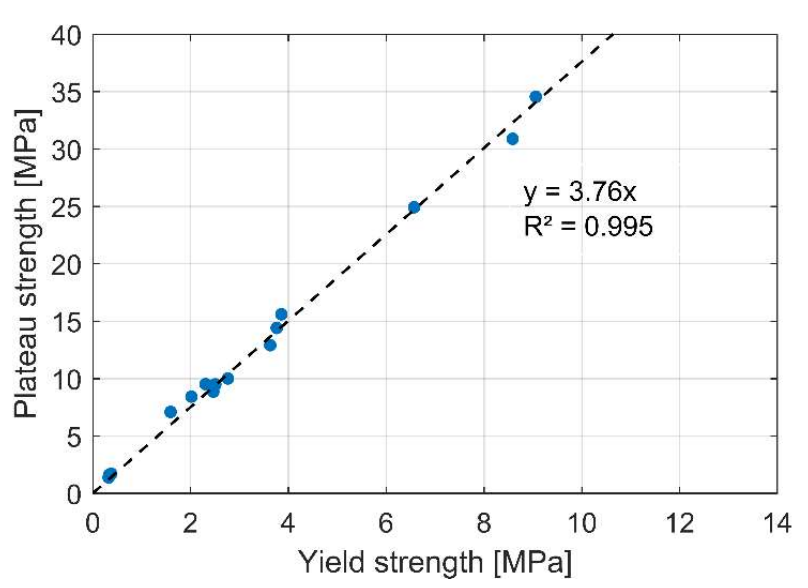

(c)

Fig. 6-Comparisons on the measured yield strength and plateau strength of the three groups of foam concrete samples: (a) Group C, (b) Group HF, and (c) Group HW. (Note: $1 \mathrm{MPa}=$ $145.038 \mathrm{psi})$

\section{Using foam modulus to estimate the crushing strengths}

In Background Section, it is proposed to use Eq. 8 for describing the foam concrete modulusto-strength relationship, which is nonrelevant to density, age, and base mixture. This equation was examined using the experimental data of relative density (Table 1), yield strength (Table 2), and foam modulus (Table 3) to seek the best correlation through data fitting. Considering Eq. 2 and 5, constant a should equal to 1; however, it is more likely to be 2 as indicated by Eq. 3 and 6. Coincidentally, the automated fitting optimization in MATLAB found the best fit when 
a equals to 1.905 , suggesting constant a should be 2 . Subsequently, the constant b was determined as -0.5 . Then, $\mathrm{k}$ was determined to be $7.5 \times 10^{-7}$. After plugging these values into Eq.8, we have Eq. 10 for the yield strength estimation:

$$
\sigma_{f c}=7.5 \times 10^{-7} E^{2}\left(\frac{\rho}{\rho_{s}}\right)^{-0.5}
$$

An excellent agreement is found between the measured yield strength and the prediction obtained using Eq.10, as shown in Fig. 7. Eq.10 provides an accurate yield strength estimation for each individual sample group, meaning that the prediction is not noticeably affected by variations in the hardened paste. Similarly, the influence of age and foam density is insignificant. Therefore, the yield strength prediction based on Eq.10 remains desirable against the different variations considered in this study.

Adding a term $r_{s}$ of the yield-to-plateau strength ratio to Eq. 10, the plateau strength can be calculated as Eq. 11:

$$
\sigma_{p l}=7.5 \times 10^{-7} r_{s} E^{2}\left(\frac{\rho}{\rho_{s}}\right)^{-0.5}
$$

where $r_{s}$ is the plateau-to-yield strength ratio. Determination of the plateau-to-yield strength ratios for Groups $\mathrm{C}, \mathrm{HF}$, and $\mathrm{HW}$ samples has been addressed in the last section. The predicted plateau strength results are compared with the experimental measurements in Fig. 8, where decent agreement is achieved for the individual groups. For the $0.4 \mathrm{~g} / \mathrm{cm}^{3}(25 \mathrm{pcf})$ samples, the data points are consistently, yet not much, off the fitted curve. This is likely to be a foam instability issue. ${ }^{6}$ At such a density, the fresh paste cannot provide enough confining force to stabilize the air bubbles, leading to a degradation of the foam structure.

Overall, the results presented in Fig. 7 and $\mathbf{8}$ support using foam modulus to estimate the crushing strengths of foam concrete. The good agreement on the predictions encourages using the proposed modulus-strength relationships for the subsequent studies. 


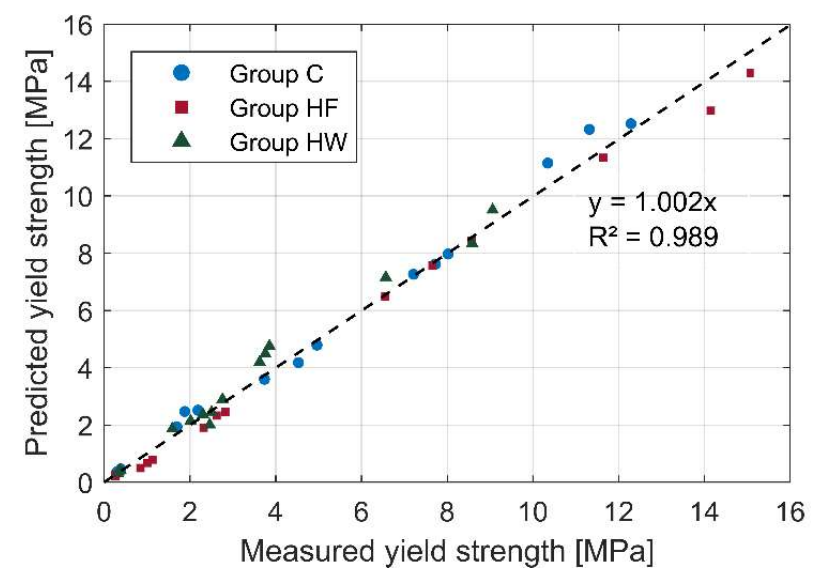

Fig. 7-A comparison on foam concrete yield strength between the measured results and the values predicted by the purposed equation. (Note: $1 \mathrm{MPa}=145.038 \mathrm{psi}$ )

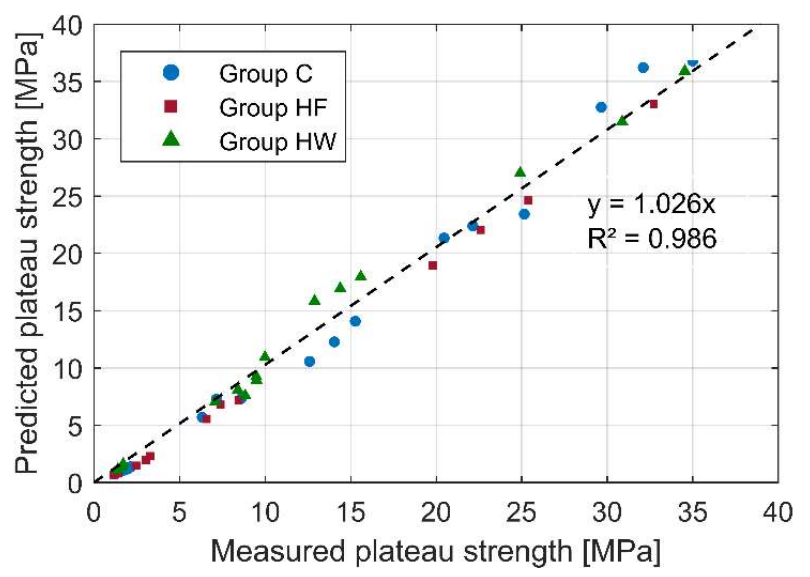

Fig. 8-A comparison on foam concrete plateau strength between the measured results and the values predicted by the purposed equation. The yield-to-plateau strength ratios for different sample groups are considered individually in this case. (Note: $1 \mathrm{MPa}=145.038 \mathrm{psi}$ )

\section{Using solid modulus to estimate the crushing strengths}

If foam modulus can be used to predict the crushing strengths, it should be plausible to use solid modulus. Substituting the foam modulus in Eq.11 with solid modulus, the foam concrete yield strength can be estimated based on solid modulus:

$$
\sigma_{f c}=7.5 \times 10^{-7} E_{s}^{2}\left(\frac{\rho}{\rho_{s}}\right)^{3.5}
$$

This approach provides practical convenience for estimating foam concrete crushing 
property without testing on foam concrete with the special experimental apparatus. Based on the solid modulus values of the paste mixtures measured from $\mathrm{C}_{-}$solid, HF_solid, and HW_solid (Table 3), the yield strength of the foamed samples is estimated using Eq.12 and further compared with the experimental result (Table 2) in Fig. 9. As suggested by the wider scatter as well as the smaller $\mathrm{R}^{2}$ value, the prediction with Eq. 12, b, based on solid modulus, is less accurate than with Eq. 12, based on foam modulus. This degradation is expected, as the input $\mathrm{E}_{\mathrm{s}}$ is not a foam property. However, Eq. 12 still provides reasonable yield strength estimation for most of the samples. In a similar manner to Eq. 11, a rough estimation on the plateau strength could be further obtained:

$$
\sigma_{p l}=7.5 \times 10^{-7} r_{s} E_{s}^{2}\left(\frac{\rho}{\rho_{s}}\right)^{3.5}
$$

From an engineering perspective, these findings provide important insights into the crushing properties of foam concrete. The problem of evaluating foam concrete crushing strengths is largely simplified by Eq.12 and 13. As the hardened paste property is now fully separated from the foam property (i.e., relative density), this approach can serve as the starting point in the material design for foam concrete of certain strength.

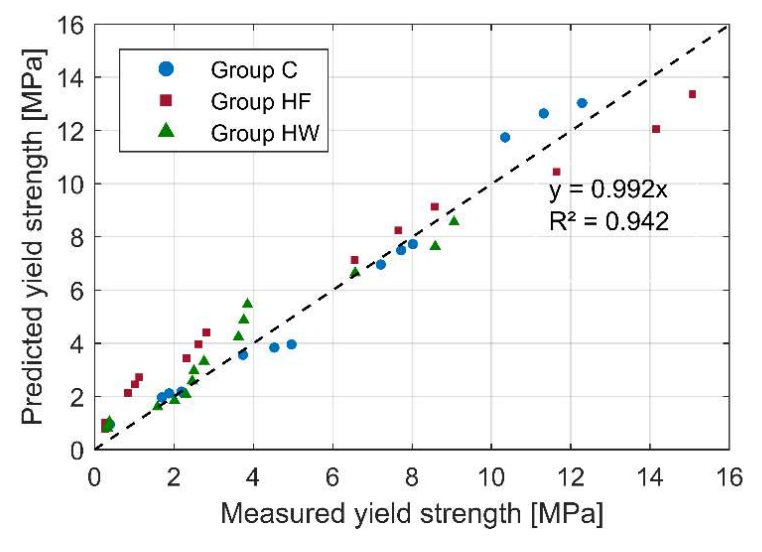

Fig. 9-A comparison on foam concrete yield strength between the measured results and the values predicted using the solid modulus of the three paste mixtures. (Note: $1 \mathrm{MPa}=145.038$ psi) 


\section{CONCLUSIONS}

Low-density foam concrete has a crushing behavior distinctively differently than we see in conventional concrete materials. Its highly crushable nature allows a substantial amount of energy being dissipated. This unique property leads to novel applications of using this material as an energy absorber. For better understanding foam concrete crushing behavior and property, this study investigated foamed cement paste samples of different paste mixtures and densities of 0.4 to $0.8 \mathrm{~g} / \mathrm{cm}^{3}$ ( 25 to $50 \mathrm{pcf}$ ). Penetration test and resonant frequency test were conducted to record the foam concrete load-displacement response under indentation and measure dynamic Young's modulus of the samples, respectively.

Based observations on the loading-displacement result, a four-phase crushing process was proposed to generalize the foam concrete crushing behavior. Yield strength and plateau strength, which are identified at the two ends of the build-up phase, were determined as the crushing strengths of this material. It was found that both the strengths were influenced by the hardened paste property through age and paste mixture and the foam geometry through relative density. The ratios between plateau strength to yield strength remained constant throughout the different density samples of the same paste mixtures. The foam modulus was observed to increase in coordinate with the crushing strength, where similar influence from age, foam density, and the solid modulus of the hardened paste were seen.

The most significant finding to emerge from this study is that crushing strengths of lowdensity foam concrete can be predicted by knowing the foam modulus and the relative density. For the strength prediction, an excellent agreement is found between the experimental data and the values given by the proposed equations. Furthermore, the degree of the correlation is determined to be irrelevant to factors like sample age and density. Based on this understanding, the strength contribution from the hardened paste property as solid modulus is successfully separated from the foam geometry as relative density. This knowledge advancement provides 
meaningful insight into understanding foam concrete crushing property, as the studies on conventional concrete can be used to shed light on the foam concrete research.

\section{ACKNOWLEDGMENTS}

The authors would like to acknowledge funding from the University Transportation Center for Research on Concrete Applications for Sustainable Transportation (RE-CAST), the O'Hare Modernization Program, and the Chicago Department of Aviation (CDA).

\section{REFERENCES}

1. Jones, M. R.; and McCarthy, A., "Behaviour and assessment of foamed concrete for construction applications," Use of Foamed Concrete in Construction, Thomas Telford Publishing, Scotland, UK, July 2005, pp. 62-88.

2. Jones, M. R.; and McCarthy, A., "Preliminary views on the potential of foamed concrete as a structural material," Mag. Concr. Res., V. 57, No.1, 2005, pp.21-31.

3. She, W.; Zhang, Y.; and Jones, M. R., "Using the ultrasonic wave transmission method to study the setting behavior of foamed concrete," Constr. Build. Mater., V. 51, 2014, pp. $62-74$.

4. ACI Committee 523, "523.3R-14: Guide for Cellular Concretes above $50 \mathrm{lb} / \mathrm{ft} 3$ (800 kg/m3)," 2014.

5. ACI Committee 229, "229R-13 Report on Controlled Low-Strength Materials," 2013.

6. Jones, M. R.; Ozlutas, K.; and Zheng, L., "Stability and instability of foamed concrete," Mag. Concr. Res., V. 68, No. 11, 2016, pp.542-549.

7. Narayanan, N.; and Ramamurthy, K., "Structure and properties of aerated concrete: A 
review," Cem. Concr. Compos., V. 22, No. 5, 2000, pp. 321-329.

8. Ramamurthy, K.; Kunhanandan Nambiar, E. K.; and Indu Siva Ranjani, G. A, "Classification of studies on properties of foam concrete," Cem. Concr. Compos., V. 31, No.6, 2009, pp. 388-396.

9. Valore, R. C., "Cellular Concretes Part 2 Physical Properties," ACI J. Proc., V. 50, 1954, pp. 817-836.

10. Amran, Y. H. M.; Farzadnia, N.; and Ali, A. A. A., "Properties and applications of foamed concrete; A review," Constr. Build. Mater., V. 101, 2015, pp. 990-1005.

11. Nambiar, E. K. K.; and Ramamurthy, K., "Shrinkage behavior of foam concrete", $J$. Mater. Civ. Eng. V. 21, No. 11, 2009, pp. 631-636.

12. Jones, M. R.; and McCarthy, A., "Heat of hydration in foamed concrete: Effect of mix constituents and plastic density," Cem. Concr. Res., V. 36, No. 6, 2006, pp. 1032 1041.

13. Tam, C. T.; Lim, T. Y.; Ravindrarajah, R. S.; and Lee, S. L., "Relationship between strength and volumetric composition of moist-cured cellular concrete," Mag. Concr. Res., V. 39, No. 138, 1987, pp. 12-18.

14. Fujiwara H.; Sawada E.; and Ishikawa Y., "Manufacture of high-strength aerated concrete containing silica fume," ACI Spec. Publ., V. 153, 1995, pp. 779-794.

15. De Rose, L.; and Morris, J., The influence of mix design on the properties of microcellular concrete, Thomas Telford: London, UK, 1999.

16. Chen, B.; Wu, Z.; and Liu N., "Experimental Research on Properties of High-Strength Foamed Concrete," J. Mater. Civ. Eng., V. 24, No.1, 2012, pp. 113-118.

17. Kearsley, E. P.; and Wainwright, P. J., "The effect of high fly ash content on the 
compressive strength of foamed concrete," Cem. Concr. Res., V. 31, No. 1, 2001, pp. $105-112$.

18. Tarasov, A. S.; Kearsley, E. P.; Kolomatskiy, A. S; and Mostert, H. F., "Heat evolution due to cement hydration in foamed concrete," Mag. Concr. Res., V. 62, No. 12, 2010, pp. 895-906.

19. Panesar, D. K., "Cellular concrete properties and the effect of synthetic and protein foaming agents," Constr. Build. Mater., V. 44, 2013, pp. 575-584.

20. Kearsley, E. P.; and Booysens, P., "Reinforced foamed concrete- can it be durable," Concrete Beton, V. 91, 1998, pp. 5-9.

21. Nambiar, E. K. K.; and Ramamurthy, K., "Influence of filler type on the properties of foam concrete," Cem. Concr. Compos., V. 8, No. 5, 2006, pp. 475-480.

22. Nambiar, E. K. K.; and Ramamurthy, K., "Models relating mixture composition to the density and strength of foam concrete using response surface methodology," Cem. Concr. Compos., V. 28, No. 9, 2006, pp.752-760.

23. Byun, K.; Song, H.; Park, S; and Song, Y., "Development of structural lightweight foamed concrete using polymer foam agent," ICPIC, 1998.

24. Zhang, Z. Q.; Yang, J. L.; and Li, Q. M., "An analytical model of foamed concrete aircraft arresting system," Int. J. Impact Eng., V. 61, 2013, pp. 1-12.

25. Santagata, E.; Bassani, M.; and Sacchi, E., "Performance of new materials for aircraft arrestor beds,". Transp. Res. Rec., No. 2117, 2010, pp. 124-131.

26. Wang, J.; Guo, W.; Zhao, R.; Shi, Y.; and Zeng, L., "Energy-absorbing properties and crushing flow stress equation of lightweight foamed concrete," J. Civil, Archit. Environ. Eng., V. 35, No. 6, 2013, pp. 96-102. 
27. Jiang, C.; Yao, H.; Xiao, X.; Kong, X.; and Shi, Y., "Phenomena of Foamed Concrete under Rolling of Aircraft Wheels," J. Phys. Conf. Ser., V. 495, No. 1, 2014.

28. McCormick, F., "Rational proportioning of preformed foam cellular concrete," ACI J. Proc., V. 64, No. 2, 1967, pp. 104-110.

29. Song, Y.; and Lange, D. A., "Measuring Young's modulus of low-density foam concrete using resonant frequency test," ASTM JOTE, (under review).

30. Gibson, L. J.; and Ashby, M. F., Cellular Solids. Cambridge University Press, 1997.

31. Ashby, M. F.; and Medalist, R. F. M., "The mechanical properties of cellular solids," Metall. Trans. A, V. 14, No. 9, 1983, pp. 1755-1769.

32. Birchall, J. D.; Howard, A. J.; and Kendall, K., "Flexural strength and porosity of cements," Nature, No. 289, 1981, pp. 388-390.

33. Yusuf, I. T.; Jimoh, Y. A.; and Salami, W. A., "An appropriate relationship between flexural strength and compressive strength of palm kernel shell concrete," Alexandria Eng. J., V. 55, No. 2, 2016, pp. 1553-1562.

34. ACI Committee 318. "318-14: Building Code Requirements for Structural Concrete and Commentary," 2014.

35. ASTM C796 / C796M-12, Standard Test Method for Foaming Agents for Use in Producing Cellular Concrete Using Preformed Foam, ASTM International, West Conshohocken, PA, 2012.

36. ASTM C305-14, Standard Practice for Mechanical Mixing of Hydraulic Cement Pastes and Mortars of Plastic Consistency, ASTM International, West Conshohocken, PA, 2014.

37. Zhou, Q.; and Mayer, R. R., "Characterization of Aluminum Honeycomb Material 
Failure in Large Deformation Compression, Shear, and Tearing," J. Eng. Mater.

Technol., V. 124, No. 4, 2002, pp. 412-420.

38. Ramamurty, U.; and Kumaran, M. C., "Mechanical property extraction through conical indentation of a closed-cell aluminum foam" Acta Materialia, V. 52, No. 1, 2004, pp. 181-189.

39. Reddy, T. Y.; Wen, H. M.; Reid, S. R.; and Soden, P. D., "Dynamic perforation of composite sandwich panels by projectiles with hemispherical and conical tips," ASMEPUBLICATIONS-PVP, No. 351, 1996, pp. 151-164.

40. Wen, H. M.; Reddy, T. Y.; Reid, S. R; and Soden, P. D., "Indentation, Penetration and Perforation of Composite Laminate and Sandwich Panels under Quasi-Static and Projectile Loading," Key Eng. Mater., V. 141, 1998, pp. 501-552.

41. Barsotti, M. A.; Puryear, J. M. H.; and Stevens, D. J. "Developing Improved Civil Aircraft Arresting Systems," Transportation Research Board, V. 29, 2009.

42. ASTM C215-14, Standard Test Method for Fundamental Transverse, Longitudinal, and Torsional Resonant Frequencies of Concrete Specimens, ASTM International, West Conshohocken, PA, 2014.

43. Hooton, R.; Kolluru, S.; Popovics, J.; and Shah, S., "Determining Elastic Properties of Concrete Using Vibrational Resonance Frequencies of Standard Test Cylinders," Cem. Concr. Aggregates, V. 22, No. 2, 2000, pp. 81-89.

44. Murthy, T. G.; Huang, C.; Chandrasekar, S., "Characterization of deformation field in plane-strain indentation of metals. Journal of Physics D: Applied Physics, V. 41, No. $7,2008$.

45. Murthy, T. G.; Saldana, C.; Hudspeth, M.; and M'Saoubi, R., "Deformation field heterogeneity in punch indentation," Proc. R. Soc. A, V. 470, No. 2166, 2014. 
46. Dorner, D.: Röller, K.: and Stöckhert, B., "High temperature indentation creep tests on anhydrite - A promising first look," Solid Earth, V. 5, No. 2, 2014, pp. 805.

47. Bastawros, A. F.; Bart-Smith, H.; and Evans, A. G., "Experimental analysis of deformation mechanisms in a closed-cell aluminum alloy foam," J. Mech. Phys. Solids, V. 48. No. 2, 2000, 301-322. 